\title{
RESEARCH
}

\section{Inside out: A note on the hierarchical update of nominal modifiers}

\author{
Philippe Schlenker ${ }^{1,2,3}$ \\ ${ }^{1}$ Institut Jean-Nicod (ENS - EHESS - CNRS), Département d'Etudes Cognitives, Ecole Normale Supérieure, Paris, FR \\ 2 PSL Research University, Paris, FR \\ ${ }^{3}$ New York University, New York, US \\ philippe.schlenker@gmail.com
}

Some sentences are globally informative but still deviant because they contain an expression that is redundant relative in its local environment, as in: \#Ann is staying in Paris and she in France. In this case, the second conjunct seems to be evaluated after the first. In several frameworks, order of evaluation follows from linear order. Focusing on nominal modification in Japanese and Korean, Ingason (2016) argued that the correct notion of order is hierarchical, not linear, and he proposed that structurally higher elements are evaluated before lower elements, a conclusion that might dovetail with Romoli and Mandelkern's (2017) proposal for postposed if-clauses in conditionals. While agreeing with Ingason's conclusion that for nominal modification evaluation order is hierarchical, we amend his theory by considering sentences with several pre- or postnominal modifiers (in English, Mandarin and French). We argue that a Noun Phrase is evaluated 'inside out', starting with the head noun and adding modifiers by order of structural proximity to the head - with the result that higher modifiers are evaluated later than lower modifiers (against the 'higher is earlier' view). We explore in an Appendix how this finding can be integrated with existing accounts of evaluation order for other constituent types, such as conjunction.

Keywords: local contexts; redundancy; triviality; incremental local contexts; presupposition projection

\section{The debate about the order of dynamic updates}

Stalnaker (1978) stated two conditions that must be satisfied by an expression $E$ relative to its local context c: the presuppositions of $E$ should be entailed by c; and $E$ should be non-trivial relative to c, in the sense that neither $E$ nor its negation should be entailed by c (this requirement can be stated both for propositional and for predicative expressions). In diverse frameworks (e.g. Stalnaker 1974, Heim 1983, Schlenker 2009), the local context of an expression $E$ aggregates information provided by the context with the contribution of linguistic expressions that surround $E$. A seminal observation was that apparently symmetric connectives such as and give rise to order effects, as shown by the contrast between (1)a and (1)b: in the computation of triviality, the first conjunct is evaluated before the second. Mandelkern et al. (2019) provide detailed experimental evidence that presupposition computation follows the same order (contra the more complex picture painted by Schlenker 2008, 2009, Chemla and Schlenker 2012, and Rothschild 2008).

(1) a. Ann is in France and she is staying in Paris.

b. \#Ann is staying in Paris and she is in France. 
But what is the right notion of order? Stalnaker (1974) and Schlenker $(2008,2009)$ base their analysis on a linear, left-to-right order. ${ }^{1}$ Focusing on adjectival modification, Ingason (2016) refutes this claim: he shows on the basis of illuminating Japanese and Korean examples involving pre-nominal modifiers that the contribution of the noun is computed first despite coming second in linear terms. Thus only a hierarchical (rather than linear) analysis can account for the similarity between the English data in (2) and the Japanese data in (3).
a. John met [a woman [who is a widow]].
b. \# John met [a widow [who is a woman]]. (Ingason 2016)
a. Taro-ga [[yamome-dearu] zyosei-ni] atta. Taro-NOM [[widow-COP] woman-DAT] met
'Taro met a woman who is a widow.'
b. \#Taro-ga [[zyosei-dearu] yamome-ni] atta. Taro-NOM [[woman-COP] widow-DAT] met
'Taro met a widow who is a woman.' (Japanese; Ingason 2016)

Ingason doesn't just claim that nominal updates are hierarchical rather than linear, however; he argues that "structurally higher elements are entered into the context before lower elements". While we fully agree with Ingason that update order is hierarchical, we propose to amend his specific conclusion. We show that in English, Mandarin, and French, NP modification is computed inside out, starting from the head of the construction, and adding modifiers by structural order of proximity to the head - with the result that higher modifiers are evaluated later (not earlier) than lower modifiers.

Ingason is not alone in pursuing a 'higher is earlier' analysis of update order. The same conclusion was reached on the basis of postposed if-clauses by Romoli and Mandelkern (2017). Showing that this analysis is not right for nominal modification will thus add further constraints on theories of update order (none of which has attempted to capture all the relevant facts so far). Without attempting to propose a unified theory, we will sketch how the 'inside out' generalization can be combined with current analyses of update order, although the result isn't without cost (because it allows for construction-byconstruction stipulations).

\section{Potential theories of update order for NP modifiers}

Ingason (2016) appears to argue, like Romoli and Mandelkern (2017), that in the case of nominal modifiers, order of evaluation reflects c-command relations, an analysis we call Theory I, or 'Higher is earlier'. We will argue for Theory II ('Inside Out'), whereby order of evaluation is inside out, starting from the noun. Ingason refutes Theory III ('No vacuous modification'), according to which the data are explained by a prohibition against vacu-

\footnotetext{
${ }^{1}$ In the tradition of dynamic semantics following Heim (1983), the order of evaluation is structural but can in effect be stipulated on an operator-by-operator basis. For instance, in if $F, G$, the antecedent $F$ is taken to be evaluated before $G$ irrespective of its linear position (hence the same predictions are made for If $F$, $G$ and for $G$, if $F$ ). In the analysis of Fox (2008), the order of evaluation is left-right, as in Schlenker (2008, 2009, 2010), but possible sentence completions are in a sense defined for a fixed structure, as in (i), which only allows for replacement of constituents:
}

(i) The set of continuations of $\varphi$ at point $\alpha$ is the set of sentences that can be derived from $\varphi$ by replacing constituents that follow $\alpha$ (in the linearization of $\varphi$ with alternative constituents. (Fox 2008)

In the analysis of Schlenker $(2008,2009,2010)$, sentence completions involved all strings that could complete the beginning of the sentence, but brackets in the object language ensured that the initial structure couldn't be modified. 
ous modification. Theory IV ('No simpler equivalent alternative') is a variant of Theory III not considered by Ingason, which can account for his data but not for minor modifications of them, nor for data we discuss in this piece.

Theory I, 'Higher is earlier': (Ingason 2016, Romoli and Mandelkern 2017):

order of evaluation reflects in this case c-command relations.

Theory II, 'Inside out' (this paper): order evaluation is in this case 'inside out', starting from the innermost nominal.

Theory III, 'No vacuous modification' (refuted by Ingason): order needn't matter: vacuous modification is always deviant.

Theory IV, 'No simpler equivalent alternative' (not considered by Ingason): order needn't matter: an expression is deviant if it is equivalent to a simpler alternative (Romoli and Mandelkern 2017 Section 2.2.)

Ingason (2016) refutes Theory III ('No vacuous modification'): (5) is deviant despite the fact that the relative clause as a whole isn't trivial. The source of the deviance is arguably that within its local context, a woman is trivial, which requires that $a$ widow should be computed first. The facts are similar in Japanese, where the noun comes last, as is expected on a hierarchical account but not on a linear account.

a. \# John met [a widow [who is a teacher and a woman]].

b. John met [a woman [who is a teacher and a widow]]. (Ingason 2016)

Investigating conditionals rather than nominals, Romoli and Mandelkern (2017) consider (and discard) a more sophisticated version of this theory, which we call Theory IV ('No simpler equivalent alternative'): following Katzir (2007), they take simpler alternatives to be obtained by deletions performed on Logical Forms. ${ }^{2}$ This theory could account for Ingason's data. (5)a has a strictly simpler alternative obtained by simplifying (5) to (6), which is equivalent. But no such simplification-by-deletion is available in (5)b: by eliminating teacher or widow, we would obtain non-equivalent alternatives.

$$
\text { John met [a widow [who is a teacher]]. }
$$

Without constraints, Theory IV would make incorrect predictions for (1), as both (1)a and (1)b would be blocked. For the same reason, Theory IV makes incorrect predictions for a modification of Ingason's data (J. Romoli, p.c.): both (7)a and b are ruled out. We will see below further arguments against Theory IV in cases that do not involve conjunctions. ${ }^{3}$

\footnotetext{
${ }^{2}$ This analysis might be seen as a consequence of Katzir's theory (2007) (possibly combined with an analysis along the lines of Magri's (2009) theory of blind implicatures). In a nutshell, Katzir's theory defines an ordering on Logical Forms that takes into account both simplicity and informativity: $F$ is at least as good as $G, F \leq G$, iff (i) $F$ is an alternative of $G$, (ii) $F$ entails $G$. $F$ is strictly better than $G, F<G$, iff $F \leq G$ and not $G \leq F$. $G \leq F$ fails whenever $F$ is strictly simpler than $G$, and thus when this is the case and $F$ is equivalent to $G, F$ is strictly better than $G$, and $G$ should not have been uttered. On the assumption that the utterance of $F$ implicates that utterances strictly better than $F$ are false, we could obtain a 'blind implicature' to the effect that not $G$, and a contradiction. A slightly different way of putting the point is that, on the assumption that one should not utter $G$ is there is a strictly better $F$ that could have been uttered, $G$ will be deviant in this case. (The latter statement, without Magri's blind implicatures, might conceivably be better. Consider the sentence I met a French Frenchman, which would seem to violate the redundancy condition on modifiers. The alternative evoked is I met a Frenchman, but the latter won't end up being negated by the covert exhaustivity operator Exh [in Exh I met a French Frenchman] because it is equivalent to the target sentence, hence without further refinements one won't get the desired contradiction.)

${ }^{3}$ An anonymous reviewer suggests that we consider a variant of Theory IV in which the eliminability of modifiers $M$ is assessed incrementally, i.e. by considering only part of the linguistic environment of $M$ (see also Mary and Romoli 2016). In a linear account, one would thus assess whether eliminating $M$ leaves the truth conditions unchanged no matter how the sentence is completed. Hierarchical notions could be explored
} 
a. John met [a teacher [who is in France and is staying in Paris]].

b. \#John met [a teacher [who is staying in Paris and is in France]].

Although we do not need to take a stance on this issue, we should note that Ingason's claim that "the head noun is higher in the structure than the relative clause (...) (Partee 1975; Wiltschko 2012; 2013)" need not go without saying. ${ }^{4}$ Wiltschko (2013) (cited by Ingason) writes that restrictive relative clauses, which are the ones that are relevant here, are in fact attached higher than the head noun, as shown in (8) (she uses ARC to refer to Appositive Relative Clauses, $R R C$ for Restrictive Relative Clauses, and $D R C$ for a new category of non-restrictive, descriptive relative clauses in Austro-Bavarian - and these are indeed argued to be lower).

Three sites of attachment for three types of relative clauses in Wiltschko (2013)

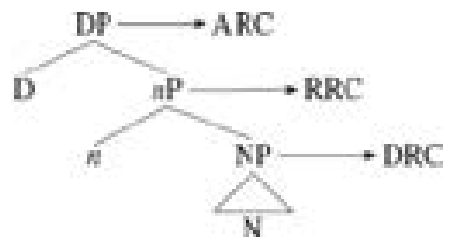

Still, because c-command order in structures of the form [Noun Relative_clause] is in part theory-internal, we will replicate Ingason's argument with structures of the form [Modifier_2 [Modifier_1 Noun]], where (i) Modifier_2 clearly asymmetrically c-commands Modifier_1, and (ii) no extent analysis we know of posits that [Modifier_1 Noun] asymmetrically c-commands Modifier_2. Despite this, we will see that Modifier_1 gets evaluated before Modifier_2.

\section{Pre-nominal modification}

\section{1 'Higher is earlier' isn't right: English}

Ingason's argument for a structural analysis of context update can be replicated with English adjectives, as is shown in (9)-(10). Unless otherwise noted, the English data are from a survey of 6 linguists who are native speakers of American English, with average

as well. We do not go in that direction because the resulting theory would be extremely close to one based on redundancy in local contexts (e.g. Theory I and Theory II). With standard theories (e.g. Schlenker 2009), if a modifier $M$ is trivial in its local context, then it is eliminable (but see Section 5.2 for some important quantifications in the present context). Whether the converse holds ("if a modifier is 'incrementally eliminable', then it is redundant in its local context") would depend on the details of a theory of incremental eliminability.

${ }^{4}$ Ingason takes it to be "uncontroversial" that the head noun is higher than the relative that modifies it. As he writes, "the relevant hierarchical facts are independently shown by the Korean reflexive caci-casin when it is bound by the head noun of a relative clause", as is illustrated in (i) (Ingason provides a further example showing that non-reflexive pronouns cannot be bound from this position, as expected by Condition B of the Binding Theory).

(i) Mary-nun [[caki-casin-ul coaha-nun] namca-lul] mannassta. Mary-top [ [caki-casin-ACC like-ADN] man-ACC] met. 'Mary met a man i $_{\mathrm{i}}$ who likes himself ${\mathrm{i} / \mathrm{k}_{\mathrm{j}}}$ '

The conclusion that the noun is higher than the relative clause might well be right, but this particular argument seems to us to be in error: on semantic grounds, a noun (of predicative type, e.g. $<\mathrm{e}, \mathrm{t}>$ ) could not be coindexed with a reflexive (which could be of type e if it is treated as a simple variable). A more natural analysis is that the reflexive is bound by a subject trace, which is itself bound by a l-abstractor, as in standard treatments (e.g. Heim and Kratzer 1998). On this view, the boldfaced constituent in (i) has the structure in (ii). The possibility of binding a reflexive under c-command (or for that matter the existence of Condition B effects, as also discussed by Ingason) says nothing about the position of noun, as it is due to the subject trace. 
acceptability judgments on a 7-point scale appearing as superscripts at the beginning of sentences; raw data can be found in the Supplementary Materials. (The same contexts will be tacitly assumed throughout, without repetition.)

(9) Context: It is known that all Hasids are Jews, although there are Jews that are not Hasids.

Under Nazi occupation, this heroic family hid...

a. $\quad{ }^{7}$ a Hasidic Jew.

b. $\quad 2.5$ a Jewish Hasid.

(10) Context: It is known that Ontario is a part of Canada.

Our company has chosen as its representative...

a. $\quad 5.2$ an Ontarian Canadian.

b. $\quad{ }^{2.3}$ a Canadian Ontarian.

The constituency alone doesn't suffice to determine c-command in this case, since it only specifies that [Hasidic Jew] and [Jewish Hasid] form constituents. But some accounts of pre-nominal modification posit that the linearly earlier adjectives are hierarchically higher, as in the following structure by Cinque 2010 (which includes additional heads; $A P$ represents the position of the adjectives):

(11) Cinque's structure for English pre-nominal adjectives

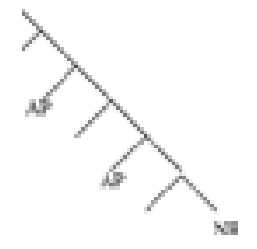

On these views, Ingason's specific conclusion makes the wrong predictions: in (9)-(10)a and (9)-(10)b alike, the noun seems to be computed first, but is predicted to be computed second on the 'higher is earlier' view combined with Cinque's structure.

Problems for the 'Higher is earlier' view become more salient when we consider cases such as (12)-(13)a,b, where constituency suffices to infer that the first adjective asymmetrically c-commands the noun. Still, the judgments suggest that the adjectives is computed after the noun for purposes of triviality assessment. It can be checked in (12)-(13)c,d that the contrast is not due to ordering restrictions on the relevant adjectives independently from the noun, since when the noun is changed so as to remove the triviality, the contrast disappears. For reasons we do not understand, (13)a,b are both degraded, although (13)b is more degraded than (13)a.

(12) Under Nazi occupation, this heroic family hid...

a. $\quad{ }^{6.3}$ a Hasidic French Jew.

b. $\quad 2$ a Jewish French Hasid.

c. $\quad{ }^{7}$ a Hasidic French child.

d. $\quad{ }^{6.5}$ a Jewish French child.

(13) Our company has chosen as its representative...
a. ${ }^{4}$ an Ontarian female Canadian.
b. $\quad 2.2$ a Canadian female Ontarian.
c. ${ }^{6}$ an Ontarian female engineer.
d. $\quad{ }^{6}$ a Canadian female engineer. 
The only way for Ingason's 'higher is earlier' theory to account for the contrasts would be to posit that even though the head noun is c-commanded by the linearly first adjective, the NP [French Hasid] in (12)b c-commands Jewish; we know of no evidence for this.

Theory III above ('No vacuous modification') cannot account for a refinement of our data, as in (14)-(15), just as Ingason showed for his.

(14) Under Nazi occupation, this heroic family hid...

a. $\quad{ }^{7}$ a Hasidic and dark-skinned French Jew.

b. $\quad 2.2$ a Jewish and dark-skinned French Hasid.

c. $\quad 6.7$ a Hasidic and dark-skinned French child.

d. $\quad{ }^{7}$ a Jewish and dark-skinned French child.

(15) Our company has chosen as its representative...

a. $\quad 5.5$ an [Ontarian and French-speaking] female Canadian.

b. $\quad 2.8$ a [Canadian and French-speaking] female Ontarian.

c. $\quad 6.7$ an [Ontarian and French-speaking] female engineer.

d. $\quad{ }^{6.7}$ a [Canadian and French-speaking] female engineer.

Both Theory II ('Inside out') and Theory IV ('No simpler equivalent alternative') are compatible with (14)-(15). But following Romoli's remark (p.c.), Theory IV fails to draw a distinction between (16)-(17)a and (16)-(17)b (as both example types are predicted to be deviant). Note that all examples are somewhat degraded, which suggests that on top of the asymmetries Ingason was interested in, some conjunctive modifiers might display a penalty for having simpler equivalent alternatives (based on the first or the second disjunct), as posited by Theory IV. Be that as it may, relative contrasts still exist within these degraded pairs, and Theory IV alone cannot account for them. ${ }^{5}$

(16) Under Nazi occupation, this heroic family hid...

a. $\quad 4.8$ a female and pregnant French refugee.

b. $\quad{ }^{2.7}$ a pregnant and female French refugee.

(17) Our company has chosen as its representative...

a. $\quad{ }^{5}$ a female and pregnant Canadian engineer.

b. $\quad{ }^{2}$ a pregnant and female Canadian engineer.

Theory II ('Inside out') only specifies how the local context of an NP modifier as a whole is computed, and thus it is silent on what happens within the modifier itself. This is compatible with an asymmetry among the two conjuncts, but to achieve this result one would need to find a way to marry the 'inside out' generalization with extent analyses of conjunction; we sketch a solution in the Appendix.

${ }^{5}$ This additional mechanism seems to be needed to account for the deviance of the following examples:

(i) Under Nazi occupation, this heroic family hid...

a. $\quad 2.3$ a Jewish and Hasidic French child.

b. ${ }^{1.5}$ a Hasidic and Jewish French child.

(ii) Our company has chosen as its representative...

a. ${ }^{2}$ a Canadian and Ontarian female engineer.

b. ${ }^{1.7}$ an Ontarian and Canadian female engineer.

We do not know why these examples are different from those involving pregnant and female (the fact that pregnant triggers a presupposition might be responsible, although a pregnant engineer doesn't seem to us to be hard to use, suggesting that this presupposition is easy to accommodate). We leave a closer analysis of conjoined modifiers for future research. 


\subsection{Ordering among modifiers: English}

Theory I ('Higher is earlier') and Theory IV ('No simpler equivalent alternative') are also refuted by cases involving stacked modifiers. Some care is needed to investigate triviality effects in such structures, as they notoriously come with severe ordering restrictions, discussed for instance in Cinque (2010) and Scontras et al. (2019). We start from a case of apparent optionality in the ordering of two adjectives, as in (18)c,d, which are both acceptable for our consultants: ${ }^{6}$

(18) Context: it is known that all Italian islands are in the Mediterranean, whereas some French islands are in the Mediterranean and some are not (e.g. some are in the Atlantic).

This is ...

a. $\quad{ }^{6.8}$ an Italian Mediterranean island.

b. $\quad 3.2$ a Mediterranean Italian island.

c. $\quad{ }^{7}$ a French Mediterranean island.

d. $\quad{ }^{6.8}$ a Mediterranean French island.

Whatever ordering facts hold between French and Mediterranean should presumably hold in identical fashion of Italian and Mediterranean. Despite this, (18)c is degraded, presumably because Mediterranean is redundant when applied to Italian island.

These facts are as expected on the 'inside out' approach: the innermost modifier and the noun are computed before the outermost modifier. They are unexpected from the perspective of Theory IV ('No simpler equivalent alternative'): since both Italian and Mediterranean are modifiers, both (18)a and (18)b should compete with the simpler but contextually equivalent sentence This is an Italian island. This correctly predicts that (18)b should be deviant, but this incorrectly predicts that (18)a should be as well. In this case, an ordering asymmetry is crucial.

\subsection{Extension to Mandarin}

The English findings about pre-nominal modification can be extended to Mandarin, where modifiers (be they adjectival or clausal) are pre-nominal as well. ${ }^{7}$ In view of the general structural similarity between pre-nominal modifiers in the two languages (modulo the difference between adjectives and relative clauses), this yields a conceptual replication of the English facts, but this also extends and diversifies the empirical base of our generalizations. Judgments are by three native speakers (also linguists), on a 7-point scale. In (19)b, the outermost modifier is redundant if update order is inside out, but not if it is left-to-right.

Context: In 1980 Berlin was divided between East and West Germany. This stopped being the case after the German reunification in $1990 .^{8}$

Wǒ de yéye shì

I of paternal-grand-father be

'My grandfather was

${ }^{6.3}$ laízì Bólín de Déguó rén.
coming Berlin DE German person. a German from Berlin.'

\footnotetext{
${ }^{6}$ As seen in the Supplementary Materials, two consultants noted that a special prosody was needed in some of these cases. In particular, one consultant wrote: "a Mediterranean French island" might require some special prosody: stress on "Mediterranean".

${ }^{7}$ Special thanks to Haoze LI, Hao LIN and Zhuoye ZHAO for help with the examples and for judgments.

${ }^{8}$ We indicate average judgments as superscripts. The full judgments are as follows, the order a., b., c., d.: Consultant 1: 7, 1, 7, 7; Consultant 2: 7, 1, 7, 7; Consultant 3: 5, 1, 56.
} 

b. ${ }^{1}$ laízì Déguó de Bólín rén. coming Germany DE Berlin person. a Berliner coming from Germany.'
c. $\quad{ }^{6.3}$ laízì Bólín de Dóng Dé rén. coming Berlin DE East German person. an East German coming from Berlin.'
d. ${ }^{6.7}$ laízì Dóng Dé de Bólín rén. coming East Germany DE Berlin person. a Berliner coming from East Germany.'

We don't know of evidence that the noun or adjective-noun combination is hierarchically higher than the relative clause. In fact, in a recent account, due to Lin and Tsai 2014, the relative clause asymmetrically c-commands the rest of the NP, as illustrated in (20).

(20) Lin and Tsai (2014) on the structure of Akiu feng de qunzi, 'a skirt which Akiu sewed'

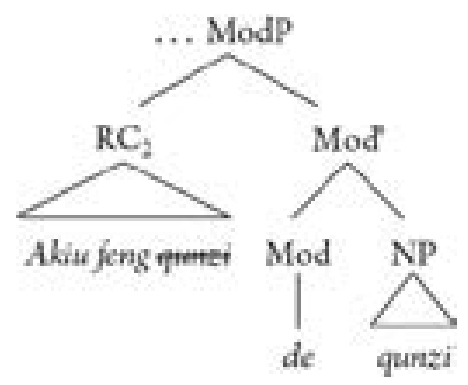

Just as our English data, these examples don't just refute Theory II ('Inside out'), but also Theory IV ('No simpler equivalent alternative'), according to which the violation stems from the fact that a modifier can be eliminated without affecting the meaning: as in the English data, this fails to explain why a redundant modifier is acceptable if it is hierarchically closer to the noun than the modifier that makes it redundant.

\section{Post-nominal modification}

We extend our generalization about 'inside out order' to French. We assume that the constituency of a doubly modified NP has the form [[NP AP1] AP2], with the linearly first modifier forming a constituent with the NP. This is the same constituency as is found in English (and Mandarin), but with a mirror-image of the word order, in accordance with standard views, such as Cinque (2010). We then discuss theoretical consequences of this finding; as we will see, depending on one's syntactic assumptions, they are compatible with an 'inside out' view or with a 'higher is earlier' view (they would be compatible with a linear (left-to-right) account as well, but we take this to have been rendered implausible by Ingason's data).

\section{1 'Inside out' order in French}

Ingason's observation that modifier update proceeds after taking into account the noun extends to French, as in (21). ${ }^{9}$ These facts are compatible with Theories I, II, III and IV, although a modification can rule out Theory III ('No vacuous modification'), as in (22). The controls in (21)c, d show that the adjectival orders in (21)a,b are not

\footnotetext{
${ }^{9}$ Contrastive judgments are those obtained by the author, confirmed with another linguist who is also a native speaker of French.
} 
the problem; rather, informativity is (note that informativity does not raise issues in the controls because personne is grammatically feminine but applicable to males and females alike).

(21) Sam a embauché une

Sam has hired a-fem

'Sam has hired a

a. femme française veuve.

woman French-fem widowed-fem

a widowed French woman.'

b. \#veuve française de sexe féminin.

widow French-fem of sex female

a female French widow.'

c. personne française veuve.

person-fem French widowed

a widowed French person.'

d. personne française de sexe féminin.

person-fem French of sex female

female French person.'

(22) Sam a embauché une

Sam has hired a-fem

'Sam has hired a

a. femme française [veuve et âgée]. woman French-fem widowed-fem and senior

a widowed and senior French woman.'

b. \#veuve française [de sexe féminin et âgée]. widow French-fem of sex female and senior a female and senior French widow.'

Theory IV ('No simpler equivalent alternative') is ruled out by examples with several modifiers, as in (23) and (24); in both paradigms, controls are needed to show that, independent from issues of informativity, both adjectival orders are possible.

(23) Context: In 1980 Berlin was divided between East and West Germany. This stopped being the case after the German reunification in 1990.

Uttered in 2019:

a. ?Ceci est une adresse allemande berlinoise.

This is an address German Berliner

'This is a Berliner German address.'

b. \#Ceci est une adresse berlinoise allemande.

This is an address Berliner German

'This is a German Berliner address.'

Uttered in 1980:

c. ?Ceci est une adresse est-allemande berlinoise.

This is an address East-German Berliner

d. Ceci est une adresse berlinoise est-allemande.

This is an address Berliner East-German

The same paradigm can be replicated in another case, as in (24): 
(24) Context: it is known that all Italian islands are in the Mediterranean, whereas some French islands are in the Mediterranean and some are not (e.g. some are in the Atlantic).

a. Ceci est une île méditerranéenne italienne.

This is an island Mediterranean Italian

'This is an Italian Mediterranean island.'

b. \#Ceci est une île italienne méditerranéenne.

This is an island Italian Mediterranean

'This is a Mediterranean Italian island.'

c. Ceci est une île méditerranéenne française.

This is an island Mediterranean French

'This is a French Mediterranean island.'

d. Ceci est une île française méditerranéenne.

This is an island French Mediterranean

'This is a Mediterranean French island.'

Ingason's argument against Theory III ('No vacuous modification') straightforwardly extends to these cases:

(25) Talking about phone numbers in 2019:

a. ?Ceci est un numéro allemand [berlinois et se terminant en 0]. This is a number German Berliner and itself ending in 0.

'This is a German number from Berlin and ending in 0.'

b. \#Ceci est un numéro berlinois [allemand et se terminant en 0]. This is a number Berliner German and itself ending in 0.

Talking about phone numbers in 1980:

c. ?Ceci est un numéro est-allemand [berlinois et se terminant en 0]. This is a number East-German Berliner and itself ending in 0.

'This is an East-German number from Berlin and ending in 0.'

d. Ceci est un numéro berlinois [est-allemand et se terminant en 0]. This is a number Berliner East-German and itself ending in 0. 'This is a Berlin East-German number ending in 0.'

\subsection{Theoretical consequences}

While these French examples could be analyzed in a left-to-right fashion, on the assumption that the analysis must be hierarchical across languages, they are compatible with an 'inside out' analysis. A 'higher is earlier' theory is possible as well if one posits some movement operations.

Post-nominal adjectival order in French or Italian tends to be the mirror-image of what is found in English. Cinque (2010) derives the Romance structure from the English structure via movement, as in (26).

(26) Cinque's derivation of post-nominal adjectival order in Romance

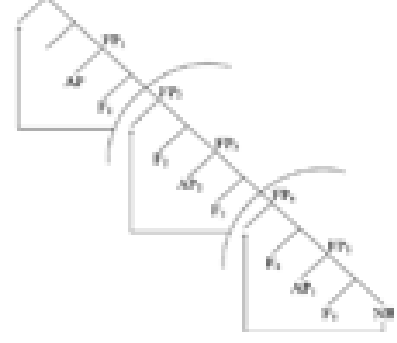


Starting from a structure [...AP2... [...AP1 NP], a first NP-movement leads to [...AP2... [NP ...AP1] ], and a second movement of the entire bold-faced constituent leads to [ [NP ...AP1] ...AP2...]. In the end, the constituency is the same as in the English structure, as seen in (27), but the linear order of the adjectives is the mirror-image of that found in English, which matters in view of known restrictions on this order. One could of course state directly that adjectives are base-generated in English as in (27)a and in Romance as in (27)b, at the cost of losing Cinque's particular account of ordering constraints on adjectives: for him, they follow from a universal hierarchy of functional heads $\mathrm{F} 1, \ldots, \mathrm{F} 5, \ldots$, which select different adjectival types, as seen in (26).
English vs. Romance constituency
a. English: [AP2 [AP1 NP]]
b. Romance: [[NP AP1] AP2]

On Cinque's view, the functional structure found in (26) (a more detailed version of (11) above) leads one to expect that completely different relations of asymmetric c-command should be found in English and in Romance: although the basic structural relations are the same, they get modified by NP movement in Romance, thence the differences stated in (28).
Asymmetric c-command relations with Cinque's structure in (26)
a. English:
$\mathrm{AP} 2>\mathrm{AP} 1>\mathrm{NP}$
b. Romance (after movements):
$\mathrm{AP} 2>[\mathrm{AP} 1 \mathrm{NP}]$
$\mathrm{NP}>\mathrm{AP} 1$
$[\mathrm{NP}$ AP1] $>$ AP2

On Theory I ('Higher is earlier'), the Romance c-command relations in (28)b are compatible with the French data, but they derive from an analysis of English that isn't, since on this view of the functional structure English would lead one to expect that AP2 is evaluated before [AP1 NP], as shown in (28)a. This means that either Cinque's analysis is incorrect, or update order based on asymmetric c-command needs to be revised.

It should be added that on a base-generation view of the structure in (27), one won't derive the correct c-command relations either without positing further covert functional structure: we would need to somehow obtain the result that in (27)a, despite the constituency, $N P$ asymmetrically c-commands $A P 1$, and [NP AP1] asymmetrically c-commands $A P 2$. We know of no evidence for a covert functional structure with these consequences.

\subsection{Interim summary}

Ingason's own data are compatible with Theory I ('Higher is earlier'), but only if one assumes that the head noun c-commands the relative clause, which need not go without saying. The data we adduced from English and Mandarin suggest that the 'inside out' generalization is correct - against the 'higher is earlier' view. The French data are compatible with the 'inside out' theory. In addition, on the assumption that there are Cinque-style movement operations that modify the initial c-command relations as in (26), 'higher is earlier' could also account for our French data. ${ }^{10}$

\section{Computing local contexts in NP's}

How should the local contexts of NP modifiers be computed? This could be specified as part of a recursive semantic procedure, as in dynamic semantics (in the spirit of Heim 1983, who did not discuss modifiers, however). This analysis has been criticized as insuf-

\footnotetext{
${ }^{10}$ We make no claim about other languages. Initial Italian data seem to pattern like French. Pre-nominal modification in German and ASL was far more complicated than we expected, and thus we recommend that the data should be explored at some future point.
} 
ficiently explanatory because $a d$ hoc assumptions can be made on an operator-by-operator basis (Soames 1989, Schlenker 2008, 2009, 2010), hence an attempt to define on independent grounds (i) what local contexts are, and (ii) which order they are computed in. While we can preserve the general definition of local contexts offered in Schlenker (2009, 2010), the linear (rather than hierarchical) notion of order employed in these works is hopeless in the present case, as Ingason showed. On the other hand, no general notion of order we know of simultaneously captures the 'inside out' character of NP modifiers and other asymmetries that can be found elsewhere, for instance in conjunctions.

At this point, then, some stipulations are needed. We state them by modifying the theory of local contexts of Schlenker (2009), leaving a dynamic account for future research. We start from the extensional fragment of Schlenker (2009), adding to it intersective predicate modifiers. This restriction to intersective modification will simplify the discussion, because by definition for any intersective modifier $M$ that applies to a Noun Phrase $N, M N$ is equivalent to the conjunction of $M$ and $N$, e.g. French scientist is equivalent to French and scientist. No such equivalence holds for competent scientist or fake scientist: in the first case, we have a modifier that is restrictive (or 'subsective'), but not intersective, as in this case the conjunction wouldn't be equivalent to the meaning we obtain (as Sam can be competent, e.g. as a plumber, without being competent as a scientist, hence Sam is a competent scientist doesn't mean that Sam is competent and Sam is a scientist). In the case of fake scientist, the modification isn't even restrictive, since fake scientists aren't scientists. Besides issues of simplicity, these differences will matter for the computation of local contexts.

\subsection{Initial definition}

As stated in (29), Schlenker $(2009,2010)$ defined the local context of an expression $d$ in a string $a d b$ as the strongest conjunctive restriction one could add in advance of computing the value of $d$, in such a way that this conjunctive restriction does not change the truth conditions relative to the global context. But this comes with a linear bias: this condition should be satisfied at the point at which the relevant position is processed, from left to right, no matter how the sentence continues afterwards. This accounts for the fact that the local context of $p$ in ( $p$ and $q$ ) does not have access to $q$ : the local context is computed without access to information about $q$, and the reason is based on linear order, not structure. By contrast, the local context of $q$ does have access to $p$, hence the asymmetry noted in (1).

(29) Local contexts in Schlenker $(2009,2010)$

The local context of an expression $d$ of propositional or predicative type which occurs in a syntactic environment $a_{-} b$ in a context $C$ is the strongest proposition or property $\mathrm{x}$ which guarantees that for any expression $d^{\prime}$ of the same type as $d$, for all strings $b^{\prime}$ for which $a d^{\prime} b^{\prime}$ ' is a well-formed sentence,

$$
\mathrm{C} \models \mathrm{c}^{\mathrm{c}^{\prime} \rightarrow \mathrm{x}} \mathrm{a}\left(\mathrm{c}^{\prime} \text { and d') b' } \Leftrightarrow \mathrm{a} \mathrm{d}^{\prime} \mathrm{b}^{\prime}\right.
$$

(If no strongest proposition or property $\mathrm{x}$ with the desired characteristics exists, the local context of $d$ does not exist.) ${ }^{11}$

Before we define a hierarchical notion of local context for restrictive modifiers, we note that the condition in (29) can be given a more abstract form. Starting from a sentence $a$ $d b$, the goal is to compute the local context of the position filled by $d$, namely $\_$in $a_{-} b$. The procedure does so by defining a set of alternatives to $a_{-} b$, of the form $a^{\prime} b^{\prime}$, and it requires that for all these alternatives, for any $d^{\prime}$ of the same type as $d, a^{\prime}$ ( $c^{\prime}$ and $d^{\prime}$ ) $b^{\prime}$ should be equivalent to $a^{\prime} d^{\prime} b^{\prime}$. Because the account has a linear bias, $a$ can be taken as

\footnotetext{
${ }^{11}$ See Schlenker (2009) for a discussion of the case in which local contexts do not exist.
} 
fixed and hence $a^{\prime}=a$, but once the linear bias is revised, one may need to consider other alternatives.

\section{General form of (29)}

The local context of an expression $d$ of propositional or predicative type which occurs in a syntactic environment $a_{-} b$ in a context $C$ is the strongest proposition or property $\mathrm{x}$ which guarantees that for any expression $d^{\prime}$ of the same type as $d$, for all appropriately defined alternatives $a^{\prime} \_b$ ' to $a_{-} b$,

$$
C \models{ }^{c^{\prime} \rightarrow x} a^{\prime}\left(c^{\prime} \text { and d') b' } \Leftrightarrow a^{\prime} d^{\prime} b^{\prime}\right.
$$

Concretely, then, when there is a linear bias, we use the rule in (30) with a' $=a$, while b' ranges over all possible ways to complete the sentence. Schlenker (2009) also considers a symmetric algorithm to compute local contexts, in which the end of the context is taken as given. This (very different) algorithm can be obtained from (30) by setting a' $=\mathrm{a}$ and $\mathrm{b}^{\prime}=\mathrm{b}$.

Because we are revising the linear bias but do not wish to commit to a definition of the alternative strings to consider, we adopt for the moment the more abstract definition in (30), and now focus on sentences of the form $a M N b$, where $N$ is a Noun Phrase and $M$ is an NP modifier. The local context $c^{\prime}$ of $M$ will be defined as the strongest conjunctive restriction one can add in such a way that no matter what $M$ turns out to be, the truth conditions won't be affected by the presence of $c^{\prime}$. For notational simplicity, we will boldface expressions to refer to their semantic value. Thus a predicate $N$ has as its semantics value $\mathbf{N}$. Furthermore, we assess all semantic types relative to a world of evaluation. Thus we will say that a predicate $N$ has type $<\mathrm{e}, \mathrm{t}>$ because $\mathbf{N}(\mathrm{w})$, also written as $\mathbf{N}^{\mathrm{w}}$ if one thinks of $\mathrm{w}$ as a parameter, has the type $<\mathrm{e}, \mathrm{t}>$ (in some technical discussions we will need to use the full type $<\mathrm{s},<\mathrm{e}, \mathrm{t}>>$ ).

(31) Local context of an intersective modifier $M$ modifying an NP $N$ in a structure $[M N]$ (or $[N M]$ : linear order irrelevant) ${ }^{12}$

The local context of a restrictive modifier $M$ of type $<\mathrm{e}, \mathrm{t}>$ modifying a Noun Phrase $N$ of type $<\mathrm{e}, \mathrm{t}>$ in a sentence $a M N b$ in a context $\mathrm{C}$ is the strongest $\mathrm{x}$ of type $<\mathrm{e}, \mathrm{t}>$ which guarantees that for any $M^{\prime}$ of type $<\mathrm{e}, \mathrm{t}>$, for all (appropriately defined) alternatives $a^{\prime} b_{-}$' to $a_{-} b$,

a. $\quad \mathrm{C} \models^{\mathrm{c}^{\prime} \rightarrow \mathrm{x}} \mathrm{a}^{\prime}\left(\left(\mathrm{c}^{\prime}\right.\right.$ and $\left.\left.\mathrm{M}^{\prime}\right) \mathrm{N}\right) \mathrm{b}^{\prime} \Leftrightarrow \mathrm{a}^{\prime} \mathrm{M}^{\prime} \mathrm{N}^{\prime}$

or equivalently (because the modifiers are all intersective),

b. $\quad C \models^{\mathrm{c}^{\prime} \rightarrow \mathrm{x}}$ a' ( $\mathrm{N}$ and ( $\mathrm{c}^{\prime}$ and $\left.\mathrm{M}^{\prime}\right)$ ) b' $\Leftrightarrow \mathrm{a}^{\prime}\left(\mathrm{N}\right.$ and $\left.\mathrm{M}^{\prime}\right) \mathrm{N} \mathrm{b}^{\prime}$

While (31)a is the 'official' definition of the local context of the modifier $M$ in a sentence ... $M N . .$. , the equivalent one in (31)b yields a very simple interpretation, as the latter is

\footnotetext{
$\overline{12}$ As in Rooth and Partee (1982), propositional conjunction is 'lifted' to apply to non-propositional arguments
} whose type 'ends in t', thanks to the recursive rule in (i)

(i) a. If d and d' are two arguments of type t, (d and d') has its 'normal' value.

b. If $d$ and d' are two arguments of a conjoinable type $<a, b>$, (d and d') $=\lambda x_{a} \cdot d(x)$ and $d^{\prime}(x)$.

It will be useful to also have a derived rule with a world parameter, as in (ii), with the definition of extensional function application in (iii). (We write $\mathrm{f}^{\mathrm{w}}$ for $\mathrm{f}(\mathrm{w})$.)

(ii) a. If $\mathrm{d}$ and $\mathrm{d}$ ' are two arguments of type $<\mathrm{s}, \mathrm{t}>$, (d and d') ${ }^{\mathrm{w}}$ has its 'normal' value, i.e. $\mathbf{d}^{\mathrm{w}}$ and $\mathbf{d}^{\text {'w }}$.

b. If $d$ and d' are two arguments of a conjoinable type $<s,<a, b>>,\left(d \text { and } d^{\prime}\right)^{w}=\lambda x_{a} \cdot d^{w}(x)$ and $\mathrm{d}^{\mathrm{w}}(\mathrm{x})$. 
nothing but the standard definition of the local context of $M$ in a predicative conjunction ... ( $N$ and $M) \ldots .{ }^{13}$ In other words, the local context of French in a sentence of the form ... French scientist... is the same as its local context in the modified sentence ... (scientist and French)... . This, in turn, captures our generalization about 'inside out' evaluation: the local context of $M$ incorporates information about $N$, despite the fact that $M$ linearly follows $M$. If we considered a further modifier $M^{\prime}$ in a sentence ... $M^{\prime}(M N) \ldots$, its local context would be the same as that of $M^{\prime}$ in ... ( $(N$ and $M)$ and $\left.M^{\prime}\right) \ldots$, and thus it would incorporate information about both $N$ and $M$, as is desired.

To take a concrete example, consider the sentence Some journalist is a female widow. We wish to derive the fact that the local context of female makes it trivial, hence the deviance of the sentence. We treat this sentence as (Some $J$. ( $F W$ )), with $J, F$ and $W$ standing for journalist, female and widow. On the assumption that the beginning of the sentence is taken into account (as in the linear algorithm), using (31)b, the local context of $F$ is defined as in (32)a.

In a context $\mathrm{C}$, the local context of $F$ in (Some $J .(F W)$ ) is the strongest $\mathrm{x}$ of type $<\mathrm{e}, \mathrm{t}>$ which guarantees that for any $M^{\prime}$ of type $<\mathrm{e}, \mathrm{t}>$,

a. $\quad \mathrm{C} \models \models^{\mathrm{c}^{\prime} \rightarrow \mathrm{x}}$ (Some J . (W and ( $\mathrm{c}^{\prime}$ and $\left.\left.\mathrm{M}^{\prime}\right)\right)$ ) $\Leftrightarrow\left(\right.$ Some J . (W and $\left.\mathrm{M}^{\prime}\right)$ ) or equivalently, due to the meaning of Some, ${ }^{14}$

b. $\quad \mathrm{C} \models \models^{\mathrm{c}^{\prime} \rightarrow \mathrm{x}}\left(\right.$ Some $(\mathrm{J}$ and $\mathrm{W})$. ( $\mathrm{c}^{\prime}$ and $\left.\left.\mathrm{M}^{\prime}\right)\right)$ ) $\Leftrightarrow\left(\right.$ Some $(\mathrm{J}$ and $\left.\left.\mathrm{W}) . \mathrm{M}^{\prime}\right)\right)$

By thinking of ( $J$ and $W$ ) as an elementary predicate $J W$, the condition in (32)b just defines the local context of the verbal predicate $V$ in a sentence such as Some $J W V$, e.g. of smokes in Some woman journalist smokes. In this case as in others, the system of Schlenker (2009) agrees with Heim (1983) and yields a local context that incorporates information about the global context $\mathrm{C}$ and the restrictor predicate $J W:^{15}$

The value c' of the local context defined in (32) is:

$\mathbf{c}^{\prime}=\lambda \mathrm{w}_{\mathrm{s}} \lambda \mathrm{x}_{\mathrm{e}} \mathrm{C}(\mathrm{w})=1$ and $\mathrm{JW}(\mathrm{w})(\mathrm{x})=1$

It follows that Some journalist is a female widow is predicted to be deviant, as female is now entailed by its local context (since c' entails the property of being female, and also that of being a journalist).

((Note that (ii) can be obtained from (i). For (ii)a, we use (i)b, with $x$ replaced with a variable $w^{\prime}$ over worlds: $\left(\mathbf{d} \text { and } \mathbf{d}^{\prime}\right)^{\mathrm{w}}=\left(\mathbf{d}\right.$ and $\left.\mathbf{d}^{\prime}\right)(\mathrm{w})=\left[\lambda \mathrm{w}_{\mathrm{s}} \cdot \mathbf{d}\left(\mathrm{w}^{\prime}\right)\right.$ and $\left.\mathbf{d}^{\prime}\left(\mathrm{w}^{\prime}\right)\right](\mathrm{w})=\mathbf{d}(\mathrm{w})$ and $\mathbf{d}^{\prime}(\mathrm{w})$. For (ii)b, an additional step is needed, again from (i)b: $\mathbf{d}(w)$ and $\mathbf{d}^{\prime}(w)=\lambda x_{a} \cdot \mathbf{d}(w)(x)$ and $\mathbf{d}^{\prime}(w)(x)$, hence in the end $\left(d \text { and } d^{\prime}\right)^{\mathrm{w}}=\lambda x_{\mathrm{a}} \cdot d^{\mathrm{w}}(\mathrm{x})$ and $\mathbf{d}^{\mathrm{w}}(\mathrm{x})$.)

(iii) If $\mathrm{x}$ and $\mathrm{f}$ are two model-theoretic objects of types $<\mathrm{s},<\mathrm{a}, \mathrm{b}>>$ and $<\mathrm{s}$, a $>$ respectively, $[\mathrm{f}(\mathrm{x})]^{\mathrm{w}}=\mathrm{f}^{\mathrm{w}}\left(\mathrm{x}^{\mathrm{w}}\right)$

As an example, if $N$ and $N^{\prime}$ have types $<\mathrm{s}$, et $>$, we have: ( $\mathbf{N}$ and $\left.\mathbf{N}^{\prime}\right)^{\mathrm{w}}=\lambda \mathrm{x}_{\mathrm{e}} \cdot \mathbf{N}^{\mathrm{w}}(\mathrm{x})$ and $\mathbf{N}^{\mathrm{w}}(\mathrm{x})$, using (ii).

${ }^{13}$ Caution is needed before general results are used, however, since the fragment of Schlenker (2009) includes propositional but not predicative conjunction.

14 The equivalence stems from the fact that Some A B just checked whether the intersection of A and B is nonempty. As a result, (Some $J$. ( $W$ and blah) has the same meaning as (Some ( $J$ and $W$ ). blah) (in either case, we just check whether the intersection $\mathbf{J} \cap \mathbf{W} \cap \mathbf{b l a h}$ is non-empty.

${ }^{15}$ This can also be proven directly. In view of the fact that the fragment is extensional ( = the value of a formula at a word $\mathrm{w}$ only depends on the value of its component parts at $\mathrm{w}$ ), and that some is conservative, it is clear that c' as defined satisfies (32)b. To prove that this is the strongest value that satisfies this condition, suppose that for some $\mathrm{w}$, $\mathrm{x}$ such that $\mathrm{C}(\mathrm{w})=1$ and $\mathrm{JW}(\mathrm{w})(\mathrm{x})=1, \mathrm{c}^{\prime}(\mathrm{w})(\mathrm{x})=0$. Select an $M^{\prime}$ whose value satisfies $\mathbf{M}^{\prime}(\mathrm{w})=\{\mathrm{x}\}$. It is clear that at $\mathrm{w}$ (which is in $\mathrm{C}$ ), the right-hand side of $(32) \mathrm{b}$ is true, as $\mathrm{x}$ is in the intersection of JW and $\mathbf{M}^{\prime}$, while the left-hand side is false because (c' and $\mathbf{M}^{\prime}$ ) $=\varnothing$. 


\subsection{The importance of ignoring non-restrictive modifiers}

It is worth noting that the computation of local contexts will be derailed if we take into account the possibility that a modifier $F$ could be non-restrictive, and thus that the modified denotation (FW) is not included in the noun denotation $\mathbf{W}$. Types would need to be adjusted to handle such cases: nominal modifiers should now be taken to have (intensionalized version of) type <et, et $>$. For the sentence Some journalist is a female widow, we will need to revise our definition of the local context as follows (with boldfaced changes in types):

In a context $\mathrm{C}$, the local context of $F$ in (Some $J$. $(F W)$ ) is the strongest $\mathrm{x}$ of type < et, et $>$ which guarantees that for any $M$ ' of type $<$ et, et $>$,

$\mathrm{C} \models \models^{\mathrm{c}^{\prime} \rightarrow \mathrm{x}}\left(\right.$ Some J . ((c' and $\left.\left.\left.\mathrm{M}^{\prime}\right) \mathrm{W}\right)\right) \Leftrightarrow($ Some J . (M' W))

In this modified framework, the adjective female has the adjusted lexical entry in (35): ${ }^{16}$

$$
\mathbf{F}^{\mathrm{w}}=\text { female }^{\mathrm{w}}=\lambda \mathrm{f}_{<\mathrm{e}, \mathrm{t}>} \lambda \mathrm{x}_{\mathrm{e}} \mathrm{f}(\mathrm{x})=1 \text { and } \mathrm{x} \text { is female in } \mathrm{w} .
$$

We would want the definition in (34) to guarantee that the modifier female $(=F)$ is locally trivial, i.e. entailed by c' as defined in (34). But this yields the result that $F$ should itself satisfy the equivalence defining $c^{\prime}$, as is argued in (36).

For all modifier $M^{\prime}$ :

a. Replacing $M^{\prime}$ in (34) with ( $F$ and $\left.M^{\prime}\right)$, we obtain: $\mathrm{C} \models \models^{\mathrm{c}^{\prime} \rightarrow \mathrm{x}}$ (Some J . (( $\mathrm{c}^{\prime}$ and $\left(\mathrm{F}\right.$ and $\left.\left.\left.\left.\mathrm{M}^{\prime}\right)\right) \mathrm{W}\right)\right) \Leftrightarrow$ (Some J . ((F and $\left.\left.\mathrm{M}^{\prime}\right) \mathrm{W}\right)$ )

b. If the local context $\mathbf{c}^{\prime}$ entails $\mathbf{F}$ (and thus ( $c^{\prime}$ and $F$ ) is equivalent to $c^{\prime}$ ): $\mathrm{C} \models \mathrm{c}^{\prime} \rightarrow \mathrm{x}$ (Some J . (( $\mathrm{c}^{\prime}$ and $\mathrm{F}$ ) and $\left.\left.\mathrm{M}^{\prime}\right) \mathrm{W}\right) \Leftrightarrow$ (Some J . ((c' and $\left.\left.\mathrm{M}^{\prime}\right) \mathrm{W}\right)$ )

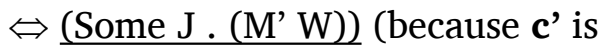
the local context)

c. It follows that the underlined expressions, which are equivalent to the same left-hand side, are also equivalent to each other:

$$
\left.\left.\mathrm{C} \models\left(\text { Some } \mathrm{J} \text {. ((F and } \mathrm{M}^{\prime}\right) \mathrm{W}\right)\right) \Leftrightarrow\left(\text { Some } \mathrm{J} \text {. ( } \mathrm{M}^{\prime} \mathrm{W}\right) \text { ) }
$$

In other words, if the modifier female is locally trivial, we derive the result that for all modifiers $M^{\prime}$, some journalist is a [female and $M^{\prime}$ '] widow should be equivalent to some journalist is an M' widow. The problem is that this result couldn't be true when one considers all the possible values of $M^{\prime}$. For instance, take $M^{\prime}=$ fake. In this case, is a fake widow has a completely different meaning from is a [female and fake] widow, as the latter reduces to is a female widow and is a fake widow, which in turn simplifies to is a widow and is a fake widow. ${ }^{17}$ So in this case the equivalence in (36)c will not hold. Which implies either

\footnotetext{
${ }^{16}$ It can be checked that with extensional function application as in fn. 12 (iii), we obtain the desired results, for instance for female engineer:
}

(i) (female engineer) ${ }^{\mathrm{w}}=$ female $^{\mathrm{w}}\left(\right.$ engineer $\left.^{\mathrm{w}}\right)=\left[\lambda \mathrm{f}_{<\mathrm{e}, \mathrm{t}} \lambda \mathrm{x}_{\mathrm{e}} \mathrm{f}(\mathrm{x})=1\right.$ and $\mathrm{x}$ is female in $\mathrm{w}]\left(\right.$ engineer $\left.^{\mathrm{w}}\right)=\lambda \mathrm{x}_{\mathrm{e}}$ engineer $^{\mathrm{w}}(\mathrm{x})=1$ and $\mathrm{x}$ is female in $\left.\mathrm{w}\right]$

${ }^{17}$ This follows from the rules in fn. 12. Technically, NP denotations are of type $<\mathrm{s}$, et $>$, and we take modifiers to be of type $<\mathrm{s}<\mathrm{et}$, et $>$. With the rules of fn. 12, we can derive the following:

(i) If $d$ and $d^{\prime}$ are (modifiers) of type $<\mathrm{s}$, < et, et $>>$, (d and $\left.d^{\prime}\right)^{\mathrm{w}}=\lambda f_{<e, t>} \cdot d^{\mathrm{w}}(\mathrm{f})$ and $\mathbf{d}^{\mathrm{w}}(\mathrm{f})$, by rule (ii) in $\mathrm{fn} .12$ $\left[=\lambda f_{<e, t>} \cdot \lambda x_{e} \cdot d^{w}(f)(x)\right.$ and $d^{\prime w}(f)(x)$, by rule (i) in fn. 12]

Thus if female and fake have type $<\mathrm{s}$, $<$ et, et $>$, and widow has type $<\mathrm{s}$, et $>$, [female and fake] ${ }^{\mathrm{w}}=$ $\lambda f_{<e, t>}$. female $(f)$ and fake ${ }^{w}(f)$, and by extensional function application (= rule (iii) in fn. 12), we have: 
that (i) our procedure to compute local contexts must somehow ignore the possibility that modifiers might be non-restrictive, or that (ii) our procedure is wrong.

Within the confines of the present discussion, we conclude that the procedure to conclude local contexts of modifiers must crucially overlook the possibility that some of them are non-restrictive.

\subsection{How can 'inside out' be integrated with broader theories of local context computation?}

As things stand, our analysis is incomplete: we haven't explained how one can integrate our definition of the local context of modifiers within general algorithms of local context computation. The problem is non-trivial because the 'inside out' evaluation of NP modifiers doesn't extend to other constituent types, hence at this point different recipes must be employed for different parts of a sentence. To illustrate the challenge, note that in (37) and (38) (= (14)a,b and (16)a,b respectively), the adjective appearing in the first conjunct of the complex modifier must be computed after the head noun (to account for the deviance of (37)b) but before the second conjunct (to account for the relative acceptability of (38)a), despite the fact that both the head noun and the second conjunct are pronounced after the first conjunct.

(37) Under Nazi occupation, this heroic family hid...

a. $\quad{ }^{7}$ a Hasidic and dark-skinned French Jew.

b. $\quad 2.2$ a Jewish and dark-skinned French Hasid.

(38) Under Nazi occupation, this heroic family hid...

a. $\quad 4.8$ a female and pregnant French refugee.

b. $\quad{ }^{2.7}$ a pregnant and female French refugee.

A systematic procedure is defined and illustrated for a simple fragment in the Appendix. Suffice it to say that it delivers the desired results, including in somewhat complex cases in which modification and conjunction are interleaved. But it crucially relies on a stipulation of order of evaluation on a construction-by-construction basis, something that leaves much to be desired if one is after an explanatory theory of local context computation.

\section{Consequences and open questions 6.1 Consequences for theories of update order}

If the 'inside out' theory of modifier update is correct, extent proposals about update order must be refined. The following theories have been entertained in the literature.

(i) Linear accounts: for these, local contexts take into account linearly earlier expressions. This was refuted for nominal modifiers by Ingason (2016); the present findings confirm his conclusions.

(ii) C-command-based accounts: Ingason (2016) proposed that "structurally higher elements are entered into the context before lower elements". Romoli and Mandelkern (2017) proposed something similar on the basis of update order in conditionals, where if-clauses are evaluated before main clauses whether they are linearly positioned before or after them. But 'higher is earlier' seems to make entirely incorrect predictions in the present case.

(ii) $\quad[$ [female and fake $]$ widow $]^{\mathrm{w}}=\left[\right.$ female and fake ${ }^{\mathrm{w}}\left(\right.$ widow $\left.^{\mathrm{w}}\right)$

$=\left[\lambda \mathrm{f}_{<\mathrm{e}, \mathrm{t}\rangle}\right.$. female $^{\mathrm{w}}(\mathrm{f})$ and fake $\left.{ }^{\mathrm{w}}(\mathrm{f})\right]\left(\right.$ widow $\left.^{\mathrm{w}}\right)$

$=$ female $^{\mathrm{w}}\left(\right.$ widow $\left.^{\mathrm{w}}\right)$ and fake ${ }^{\mathrm{w}}\left(\right.$ widow $\left.^{\mathrm{w}}\right)$

$=\lambda \mathrm{x}_{\mathrm{e}} \cdot$ female $^{\mathrm{w}}\left(\right.$ widow $\left.^{\mathrm{w}}\right)(\mathrm{x})$ and fake $^{\mathrm{w}}\left(\right.$ widow $\left.^{\mathrm{w}}\right)(\mathrm{x})$

$=\lambda \mathrm{x}_{\mathrm{e}} \cdot$ widow $^{\mathrm{w}}(\mathrm{x})$ and fake ${ }^{\mathrm{w}}\left(\right.$ widow $\left.^{\mathrm{w}}\right)(\mathrm{x}) \quad$ (because female $\mathrm{w}\left(\right.$ widow $\left.^{\mathrm{w}}\right)=$ widow $\left.^{\mathrm{w}}\right)$ 
(iii) M-command based accounts: Chierchia (2009) proposed an alternative structural account, one in which co-arguments of a functor are taken into account in order of structural proximity to that functor. So in a structure $[f A] B$, where $f$ is the functor and $A, B$ are its arguments, $A$ is structurally closer to $f$ than to $B$ is (technically: $A$ m-commands $B^{18}$ ), and for this reason the local context of $A$ doesn't take into account $B$ but the local context of $B$ does take into account $A$. If the modified nominal were a functor, the 'inside out' generalization would follow, at least when it comes to the update order of modifiers relative to each other. But a noun of type $<\mathrm{e}, \mathrm{t}>$ couldn't be the 'functor' for its modifiers. If anything, when one considers a broader class of modifiers including non-intersective ones (e.g. competent, fake), the modifiers must be given type < et, et $>$ (or intensionalized versions thereof). If so, in a structure $M^{\prime}[M N]$, where $M$ and $M^{\prime}$ are of type <et, et $>$ whereas $N$ is of type $<\mathrm{e}, \mathrm{t}>, M^{\prime}$ is a functor, but it's not the case that $M$ and $N$ are coarguments of $M^{\prime}$. Rather, $M^{\prime}$ takes a single argument, $M N$. Nothing yields the result that the update order is $N$ before $M$ before $M$ '.

(iv) Linear bias with domain-by-domain interpretation: Chung (2019) proposes that "the interpreter parses a sentence from left to right, but the local context of an expression (either propositional or predicative) can be calculated only at points where the interpreter has access to the semantic values of the parsed expressions". For him, semantic values must be propositional, and thus "the interpreter needs to postpone the calculation of local context if the parsed expressions altogether do not constitute a clause". It is immediate that this account won't extend to our data: none of the expressions we study (adjectives and nouns) are of propositional type, and thus one would expect that the modifiers and the head noun are all evaluated at once, since no propositional expression can be obtained without including them all. ${ }^{19}$

\subsection{Open questions and extensions}

This note leaves open several questions.

(i) We restricted attention to intersective nominal modifiers. But as mentioned in Section 5.2, a somewhat paradoxical result is obtained when non-restrictive modifiers such as fake are taken into account: the local contexts obtained fail to derive the triviality effects we find.

(ii) One would like to extend the empirical and theoretical investigation to other types of modifiers (e.g. clausal modifiers, verbal modifiers) - something we leave for future research. ${ }^{20}$

\footnotetext{
${ }^{18}$ Chierchia (2010) relies on the following definition: "If A and B are co-arguments of $\mathrm{f}$, A f-commands B iff the first functional complex $\mathrm{f}(\mathrm{A})$ containing A does not contain B. (= A is closer to $\mathrm{f}$ than B)"

${ }^{19}$ One connection with other research should be added. Scontras et al. (2019) argue that constraints on adjectival ordering can be given a pragmatic derivation. Instead of following Cinque's (2010) heavily syntactic analysis, they go with a generalization consonant with Scontras et al. (2017), to the effect that less 'subjective' adjectives prefer to be hierarchically closer to the head noun. They show that this generalization can be derived from a drive to restrict reference space: having the more error-prone adjectives later in the computation minimizes risk of referential identification. Crucially, however, this analysis relies on a notion of computation order. The authors take as a given that this should be order of semantic composition, but at least for intersective adjectives, any other order would yield the same semantic effect. It is thus interesting to note that the 'inside out' order derived here is exactly the one that the authors need to get their account to work.

${ }^{20}$ This line of investigation might uncover an interesting tension. Romoli and Mandelkern (2017) convincingly argue that, irrespective of its linear position, an if-clause is computed before the main clause it is attached to for purposes of dynamic update. But it might make sense to treat if-clauses (as well as whenclauses) as propositional or verbal modifiers, for instance because they are syntactically optional. If so, one would expect that they should be computed after the expressions they modify, hence after the main clauses - which is... exactly the wrong result.
} 
(iii) Assuming that 'inside out' is correct, how can it be married with update algorithms for other constructions? We have sketched an integration mechanism that yields positive results in some cases, but its properties have yet to be evaluated.

(iv) A more traditional analysis within dynamic semantics ought to be compared to the present one. This is particularly important because the absence of a general theory of update order within non-dynamic accounts threatens their explanatory force, bringing them a tad closer to the explanatory problems faced by dynamic semantics. ${ }^{21}$

(v) Most importantly, one needs to explain why the 'inside out' generalization holds. This is intimately related to the problem of finding a general algorithm that accounts for diverse constructions, since the test of any theory will in part lie in its generality.

(vi) Last, but not least, the present discussion highlights a new area of the syntax/semantics interface: the analysis of redundancy effects crucially combines insights from local context theory and from syntax. The latter is obviously essential to determine what hierarchical relations should enter into the algorithm that computes local contexts, ${ }^{22}$ and it might also matter to determine what counts as a 'modifier'. Conversely, this is an area in which semantic data might further constraint syntactic theories. In addition, a closer consideration of the syntax might conceivably offer ways to eliminate construction-byconstruction stipulations in the future.

\section{Additional File}

The additional file for this article can be found as follows:

- Appendix. Integrating 'Inside Out' with broader theories of local context computation. DOI: https://doi.org/10.5334/gjgl.1130.s1

\section{Supplementary Materials Raw data for the mini-survey of English}

Text of the survey: https://drive.google.com/file/d/1MT24fswFdBR0zYNOM0vYfDKXd8z4EWLb. Responses (6 linguists who are native speakers of American English): https://drive.google.com/file/d/10_-CrAC_FtZbx9PvA41ulltORrPixdkQ.

\section{Competing Interests}

The author has no competing interests to declare.

\section{References}

Chierchia, Gennaro. 2009. On the explanatory power of dynamic semantics. Talk presented at Sinn und Bedeutung 14, Vienna.

Chung, WooJin. 2019. Context updates in head-final languages: Linear order or hierarchy? Proceedings of Sinn Und Bedeutung 22(1). 313-329.

Cinque, Guglielmo. 2010. The Syntax of Adjectives: A Comparative Study. MIT Press. DOI: https://doi.org/10.7551/mitpress/9780262014168.001.0001

Heim, Irene \& Angelika Kratzer. 1998. Semantics in Generative Grammar. Oxford, Basil: Blackwell.

Ingason, Anton Karl. 2016. Context updates are hierarchical. Glossa 1(1). 1-9. DOI: https://doi.org/10.5334/gjgl.71

\footnotetext{
${ }^{21}$ See for instance Rothschild (2011) and Schlenker (2009, Section 3.2) for ways to constrain dynamic semantics.

${ }^{22}$ In particular, whenever some movement operations are postulated, one would need to determine whether the algorithm that computes local contexts takes into account the pre- or the post-movement structure (in case this matters). Hopefully this could be determined on independent grounds: one would expect that whatever structure is the input of semantic interpretation is also used for local context computation.
} 
Katzir, Roni. 2007. Structurally-defined alternatives. Linguistics \& Philosophy 30(6). 669- 690. DOI: https://doi.org/10.1007/s10988-008-9029-y

Lin, Jo-Wang \& Wei-Tien Dylan Tsai. 2014. Restricting Non-restrictive Relatives in Mandarin Chinese. Chinese Syntax in a Cross-Linguistic Perspective. Oxford: Oxford University Press. DOI: https://doi.org/10.1093/acprof:oso/9780199945658.003.0004

Mandelkern, Matthew \& Jacopo Romoli. 2017. Parsing and Presupposition in the calculation of local context. Semantics \& Pragmatics 10(7). DOI: https://doi.org/10.3765/ sp. 10.7

Mayr, Clemens \& Jacopo Romoli. 2016. A puzzle for theories of redundancy: exhaustification, incrementality, and the notion of local context. Semantics \& Pragmatics 9(7). DOI: https://doi.org/10.3765/sp.9.7

Romoli, Jacopo \& Matthew Mandelkern. 2017. Hierarchical structure and local contexts. In Robert Truswell, Chris Cummins, Caroline Heycock, Brian Rabern, and Hannah Rohde (eds.), Proceedings of Sinn und Bedeutung 21(2). 1017-1034.

Rooth, Mats \& Barbara Partee. 1982. Conjunction, type ambiguity and wide scope « or ». In Flickenger, D., Macken, M., and Wiegand, N. (eds.), Proceedings of the First West Coast Conference on Formal Linguistics, 1-10. Linguistics Dept, Stanford University.

Rothschild, Daniel. 2008. Presupposition projection and logical equivalence. Philosophical Perspectives 22(1). 473-497. DOI: https://doi.org/10.1111/j.1520-8583.2008.00154.x

Rothschild, Daniel. 2011. Explaining Presupposition Projection with Dynamic Semantics. Semantics \& Pragmatics 4(3). 1-43. DOI: https://doi.org/10.3765/sp.4.3

Schlenker, Philippe. 2008. Be Articulate: A Pragmatic Theory of Presupposition Projection. Theoretical Linguistics 34(3). 157-212. DOI: https://doi.org/10.1515/THLI.2008.013

Schlenker, Philippe. 2009. Local Contexts. Semantics \& Pragmatics 2(3). 1-78. DOI: https:// doi.org/10.3765/sp.2.3

Schlenker, Philippe. 2010. Presuppositions and Local Contexts. Mind 119(474). 377-391. DOI: https://doi.org/10.1093/mind/fzq032

Scontras, Gregory, Judith Degen \& Noah D. Goodman. 2017. Subjectivity predicts adjective ordering preferences. Open Mind: Discoveries in Cognitive Science 1(1). 53-65. DOI: https://doi.org/10.1162/OPMI_a_00005

Scontras, Gregory, Judith Degen \& Noah D. Goodman. 2019. On the grammatical source of adjective ordering preferences. Semantics \& Pragmatics 12. DOI: https://doi. org/10.3765/sp.12.7

Soames, Scott. 1989. Presupposition. In D. Gabbay and F. Guenthner (eds.), Handbook of Philosophical Logic IV ,553-616. Dordrecht: Springer. DOI: https://doi.org/10.1007/97894-009-1171-0_9

How to cite this article: Schlenker, Philippe. 2020. Inside out: A note on the hierarchical update of nominal modifiers. Glossa: a journal of general linguistics 5(1): 60.1-19. DOI: https://doi.org/10.5334/gjgl.1130

Published: 24 June 2020

Copyright: $\odot 2020$ The Author(s). This is an open-access article distributed under the terms of the Creative Commons Attribution 4.0 International License (CC-BY 4.0), which permits unrestricted use, distribution, and reproduction in any medium, provided the original author and source are credited. See http://creativecommons.org/licenses/by/4.0/. 